symptom perception, the principles of treatment, and the use and abuse of drugs. Much of what they say is already well known by those who have been reading the literature emanating from general practice throughout the world for the past decade or two. Much of what they say they have already said and written elsewhere-as have many others from primary care in different countries of the world, but for those new to this philosophy, these two parts of the handbook are essential reading.

Only eight sections of the seventy chapters in part 3 (The Complaint) are at present available. The symptoms covered range from dizziness, through the red eye, sore throat, cough, chest pain and diarrhoea, to difficulties with sexual intercourse and the infertile couple. The quality of the different chapters varies considerably. Whilst it is essential to emphasize the ordinary diseases met in everyday practice-and how to deal with such problems - too little attention has been paid to the possible alternative diagnoses; how the GP should investigate and when he should do so. Perhaps other chapters will be more informative in this respect. A final judgment must await completion of the book.

\section{Today's Treatment: 1}

Articles published in the British Medical Journal. Pp. 411, soft cover. British Medical Association, London, 1976. $£ 4.00$.

This book consists of articles first published in the BMJ, between 1973 and 1975 and now, according to the preface, 'collated together as a convenient working manual for doctors in clinical practice'. The subjects covered are diseases of the skin, which has thirteen articles, blood and neoplastic diseases with twenty, psychological medicine with thirteen, and diseases of the nervous system with only nine articles. Most of the articles include a brief introductory account of the pathophysiological basis of the condition, but thereafter there is no consistent pattern about the depth in which subjects are considered, whether or not drug doses are given, or about the use of references in the text and/or for further reading.
There are certain very obvious gaps in some areas as, for example, the treatment of Parkinsonism, which is nowhere dealt with fully. The index is adequate.

The articles are of practical value and lucidly written by well known specialist practitioners. However, although this review copy will form a useful addition to the bookcase on a General Medical ward with skin beds, it is a little difficult to imagine this particular combination of subjects appealing to a very large number of doctors.

\section{Tumours of the Ovary}

By H. Fox and F. A. Langley. Pp. vii +312 , hard cover, illustrated. William Heinemann Medical Books Ltd, London, 1976. £8.50.

This excellent monograph is the fruit of many years' study of ovarian tumours by Professor Langley who, as a member of the World Health Organization Panel on ovarian tumours, is acknowledged as one of the world's leading experts on this subject. The authors draw on their experience with neoplasms from women treated at St Mary's Hospital, Manchester, over the last 25 years and also with tumours submitted to the Ovarian Tumour Panels of the World Health Organization and the Royal College of Obstetricians and Gynaecologists. A stumbling block to those wishing to study ovarian tumours is the complexity and diversity of the different tumour types, so a good working classification is essential. This book adopts the WHO classification and explains it in considerable detail. The first two chapters are on the embryology and endocrinology of the gonads. The third chapter deals with the classification and the rest of the book is composed of chapters describing the individual tumour types. Not only is there a very full description of the pathology, including macroscopic and microscopic appearances, ultrastructure and histochemistry, but also a discussion of the clinical features, course, treatment and prognosis. There are numerous illustrations and the bibliography is exhaustive. This book can be recommended without reservation to both pathologists and gynaecologists, particularly as it has been produced at such a bargain price. 